\title{
Predictors of risky alcohol consumption in schoolchildren and their implications for preventing alcohol-related harm Mark A Bellis*1, Karen Hughes ${ }^{1}$, Michela Morleo' ${ }^{1}$, Karen Tocque ${ }^{1}$, Sara Hughes ${ }^{1}$, Tony Allen ${ }^{2}$, Dominic Harrison ${ }^{3}$ and Eduardo Fe-Rodriguez ${ }^{1}$
}

\author{
Address: ${ }^{1}$ Centre for Public Health, Liverpool John Moores University, Castle House, North Street, Liverpool, L3 2AY, UK, 2 Trading Standards \\ North West Under Age Sales Strategy Group, North House, 130 Rochdale Road, Oldham, OL1 2JA, UK and ${ }^{3}$ NHS North West/Department of \\ Health, Government Office North West, City Tower, Piccadilly Plaza, Manchester, M1 4BE, UK \\ Email: Mark A Bellis* - m.a.bellis@ljmu.ac.uk; Karen Hughes - k.e.hughes@ljmu.ac.uk; Michela Morleo - m.j.morleo@ljmu.ac.uk; \\ Karen Tocque - k.tocque@ljmu.ac.uk; Sara Hughes - s.k.hughes@ljmu.ac.uk; Tony Allen - tony.allen@oldham.gov.uk; \\ Dominic Harrison - dominic.harrison@dh.gsi.gov.uk; Eduardo Fe-Rodriguez - e.fe-rodriguez@ljmu.ac.uk \\ * Corresponding author
}

Published: 10 May 2007

Substance Abuse Treatment, Prevention, and Policy 2007, 2:15 doi:10.1 186/1747-597X-215

This article is available from: http://www.substanceabusepolicy.com/content/2/1//5

C 2007 Bellis et al; licensee BioMed Central Ltd.

This is an Open Access article distributed under the terms of the Creative Commons Attribution License (http://creativecommons.org/licenses/by/2.0), which permits unrestricted use, distribution, and reproduction in any medium, provided the original work is properly cited.

\section{Received: 30 November 2006}

Accepted: 10 May 2007

\begin{abstract}
Background: While alcohol-related health and social problems amongst youths are increasing internationally, both consumption and associated harms are particularly high in British youth. Youth drinking patterns, including bingeing, frequent drinking and drinking in public spaces, are associated with increased risks of acute (e.g. violence) and long-term (e.g. alcohol-dependence) health problems. Here we examine economic, behavioural and demographic factors that predict these risky drinking behaviours among 15-16 year old schoolchildren who consume alcohol. A crosssectional survey was conducted among schoolchildren in North West England $(n=10,27 I)$ using an anonymous questionnaire delivered in school settings. Analysis utilised logistic regression to identify independent predictors of risky drinking behaviour.

Results: Of all respondents, $87.9 \%$ drank alcohol. Of drinkers, 38.0\% usually binged when drinking, $24.4 \%$ were frequent drinkers and $49.8 \%$ drank in public spaces. Binge, frequent and public drinking were strongly related to expendable income and to individuals buying their own alcohol. Obtaining alcohol from friends, older siblings and adults outside shops were also predictors of risky drinking amongst drinkers. However, being bought alcohol by parents was associated with both lower bingeing and drinking in public places. Membership of youth groups/teams was in general protective despite some association with bingeing.

Conclusion: Although previous studies have examined predictors of risky drinking, our analyses of access to alcohol and youth income have highlighted eradicating underage alcohol sales and increased understanding of children's spending as key considerations in reducing risky alcohol use. Parental provision of alcohol to children in a family environment may also be important in establishing child-parent dialogues on alcohol and moderating youth consumption. However, this will require supporting parents to ensure they develop only moderate drinking behaviours in their children and only when appropriate.
\end{abstract}




\section{Background}

In recent years increasing levels of hazardous and harmful alcohol use, along with their negative health consequences, have received international attention as issues requiring immediate action. Thus, the World Health Organization (WHO) has identified excessive alcohol use as one of the most important risks to health [1] and the World Health Assembly (Resolution WHA58.26) has requested Member States to implement effective interventions to tackle alcohol misuse [2,3]. Within the WHO European Region, where per capita alcohol consumption and related disease burden are double global averages [4,5], two successive alcohol action plans (covering 1992 to 2005) have been followed by a Regional Framework providing strategic guidance to member states on the development and implementation of alcohol policy [6]. Further strategic support in the European Union (EU) has been provided through the EU strategy to assist member states in reducing alcohol-related harm [7]. In both, particular attention is focused on the increasing levels of alcohol intoxication and the disproportionate burden of alcohol-related harms in European youth.

Among schoolchildren (aged 15-16) in many European countries, hazardous and harmful drinking patterns have escalated with increases in both binge drinking (here drinking five or more alcoholic drinks in one drinking occasion) (e.g. UK, Norway, Czech Republic) and drunkenness (having ever experienced more than 20 drunken episodes) (e.g. Ireland, Estonia, Slovenia) [8]. In the long term continued heavy alcohol consumption, including frequent bingeing, is linked to pathologies including liver disease, cancers and cardiovascular disease [9-11]. However, binge drinking by youths is also associated with acute problems including alcohol-related violence and other anti-social behaviours [12,13]. Furthermore, it contributes to unprotected sex, drug consumption and educational problems including truancy [13-15].

In the UK, levels of both alcohol-related health burdens (e.g. liver disease) and crime are rising [16,17]. Approximately 7.1 million residents in England are now thought to be hazardous or harmful users of alcohol [18] with around 1.1 million being alcohol dependent [19]. Further, UK youth now have among the highest levels of alcohol consumption and binge drinking in the European Union (e.g. prevalence of binge drinking in the past 30 days among girls aged 15-16: UK 56\%, Belgium 44\%, France 23\%) [8], and experience drunkenness at an earlier age than most of their European counterparts [20]. Associated problems including anti-social behaviour [13] and unintended pregnancy [21] are also high [22,23]. Nationally, alcohol-related problems are estimated to cost approximately $£ 20$ billion per annum [24].
The reasons why alcohol creates a disproportionate health and social burden in some cultures (e.g. UK) are likely to be multi-faceted. While debate continues over whether any alcohol consumption by youths can be beneficial [25], studies suggest that drinking behaviours early in life can not only be of immediate detriment to health but may also relate to adult alcohol consumption patterns and their related health consequences [26-29]. In particular, binge drinking and unsupervised underage drinking in public places can result in negative health consequences (e.g. accidents) and are strongly linked to anti-social behaviour [30,31]. However, where alcohol is typically integrated into family life (e.g. in Mediterranean countries such as France and Italy) [25], children display lower levels of binge drinking and alcohol-related anti-social behaviour than their Northern counterparts (e.g. UK and Scandinavian countries) [8]. The consequences of frequent drinking by youths are less clear yet several studies have associated frequent youth drinking with increased health risks including involvement in physical fights [31,32].

Previous research has identified a range of factors associated with risky drinking behaviours in youths. These include those related to: the individual (e.g. sensation seeking, anxiety, positive alcohol expectancies [33]), their relationships (e.g. parental and peer drinking behaviour $[34,35])$, and the drinking context (e.g. cultural norms, alcohol availability [35]). Here however, we use a schoolbased (aged 15-16) sample of 10,271 children and focus specifically on those that drink $(n=9,029)$. We examine relationships between risk-related drinking behaviours and alcohol consumers' demographics, personal economics and access to alcohol and leisure activities. Finally, we explore how an understanding of such relationships can be used to reduce alcohol-related harm.

\section{Methods}

Within England, the North West Region (population 6.8 million) [36] has the highest number and greatest prevalence of hazardous/harmful drinkers (1.25 million) of all English Regions [19]. Previous work within the Region has already identified both substantial consumption of alcohol by young people and frequent illegal alcohol sales to those under 18 (UK minimum age of purchase is 18) [37-39]. To provide more intelligence on both issues, Trading Standards North West (the organisation responsible for enforcing legislation and regulations governing the sale of goods and services, including alcohol, in the North West of England) undertook a survey of 14 to 17 year old schoolchildren in the North West Region. Questions were anonymous and explored: basic demographics of respondents; drinking frequencies (over the past six months), types and quantities of alcohol consumed (drinks were counted in the number of bottles, cans, 
glasses and pints consumed to accommodate existing definitions of youth bingeing [8]); sources of alcohol; income available to youths; and personal views on alcohol consumption. The questionnaire consisted almost entirely of closed questions with the exception of one requesting suggestions for additional facilities for young people. The questionnaire was made freely available though local Trading Standards offices ( $\mathrm{n}=22$ covering the North West Region of England) to schools located within their administrative areas. In schools agreeing to participate, questionnaires were distributed by Trading Standards Officers to school staff (teachers and assistants) who then delivered the questionnaire to students within normal school lessons. Research methods and materials complied with the Declaration of Helsinki. Compliance levels were not recorded in each class as the sample was not intended to be representative but was opportunistic, with analyses focusing on relationships between variables recorded by individual participants. Further, while demographics such as ethnicity were included, only broad categories were used in order to obtain meaningful sample sizes in each group.

From 147 North West secondary schools (in 21 local authorities) that participated in the survey, a total of 12,883 questionnaires were returned during the sampling period (from $1^{\text {st }}$ February to $31^{\text {st }}$ March 2005). From these, 43 were excluded immediately due to completion by 18 year olds. In order to assign an approximate level of deprivation to each school, Index of Multiple Deprivation 2004 (IMD) [40] was calculated based on the Middle Super Output Area (MSOA) in which each school was located. For the North West, MSOA are geographical areas with an average total population of 7,380 (500 for those aged 15-19). Based on the IMDs of all MSOAs across the North West, each MSOA was allocated to a regional quintile of deprivation and students were allocated to quintiles based on the MSOA of their school. At this stage any schools that were not identified as local state schools (i.e. tax funded and recruiting in general from the local population) were removed from the analysis ( $\mathrm{n}=15$ schools), leaving 132 general secondary schools out of a total of 474 such schools in the North West [41]. In addition, as only $1 \%$ of pupils were 17 years old and $2 \% 14$ years old, analyses were limited to 15 to 16 year olds where adequate numbers were available. The final sample for analysis was 10,271 respondents.

Initial analyses (Table 1) examined factors predicting whether individuals drink alcohol at all (here defined as drinking at least once every six months). However, most analyses (Tables 2 and 3 ) focused on identifying predictors of whether those that consume alcohol: usually have five or more alcoholic drinks per session (here, binge drinking); usually drink at least two or more days each week (here, frequent drinking); and drink in public settings (including drinking in streets, parks, pubs and clubs and excluding drinking at home, in friends' houses and on special occasions with family and friends). From these three risk factors, two composite variables were also calculated: "any drinking risk" (having any one of the three risk factors); and "all drinking risks" (having all three risk factors). Initial chi square statistics were calculated in SPSS [42]. However, to account for confounding relationships between variables and potential underestimation of variance associated with cluster sampling $[43,44]$ STATA was utilised for logistic regression with appropriate cluster sample corrections applied [45].

\section{Results}

Of the 10,271 individuals included in the final analysis, $11.6 \%$ stated they never drank alcohol and $87.9 \%$ that they drank alcohol at least once every six months $(0.5 \%$ did not respond). Those that drank were more likely to be female, older, attend a school in the least deprived regional quintile, white or mixed race, have more spending money available per week and/or be a member of a youth or sports group. Not surprisingly, they were much more likely to purchase alcohol (than non consumers) although the majority of those that drank (60.4\%) stated that they did not buy their own alcohol.

Remaining analyses utilise only those individuals who drank alcohol ( $n=9,029 ; 87.9 \%$ of the total sample) and examine predictive factors for bingeing, frequent drinking, drinking in public settings as well as composite risk variables of "any drinking risk" and "all drinking risks" (Table 2). Overall $38.0 \%$ of drinking respondents usually binged when drinking, approximately a quarter (24.4\%) were frequent drinkers and half $(49.8 \%)$ drank in public settings. Being aged 16 (c.v. 15) and having more money to spend per week were strongly related to increases in all three individual risk factors and to both composite risk variables ("any drinking risk" and "all drinking risks"; Table 2). Males were more likely to binge and drink frequently but were no more likely to drink in public settings than females. Deprivation was linked with drinking in public settings although frequent and binge drinking were not. Ethnicity, as well as being strongly related to whether youths drank (Table 1), also affected patterns of drinking. Thus, white and mixed race youths were more likely to binge than any other group and mixed race youths were also more likely to drink in public settings (Table 2).

Personal purchase of alcohol was individually related to all risky drinking behaviours. Thus, drinking in public settings more than doubled from $33.1 \%$ in those that do not buy their own alcohol to $75.3 \%$ amongst those that do. Similarly, levels of frequent drinking more than doubled (from $16.3 \%$ to $38.8 \%$ ) and binge drinking rose from 
Table I: General sample characteristics and comparisons between those that do and do not consume alcohol

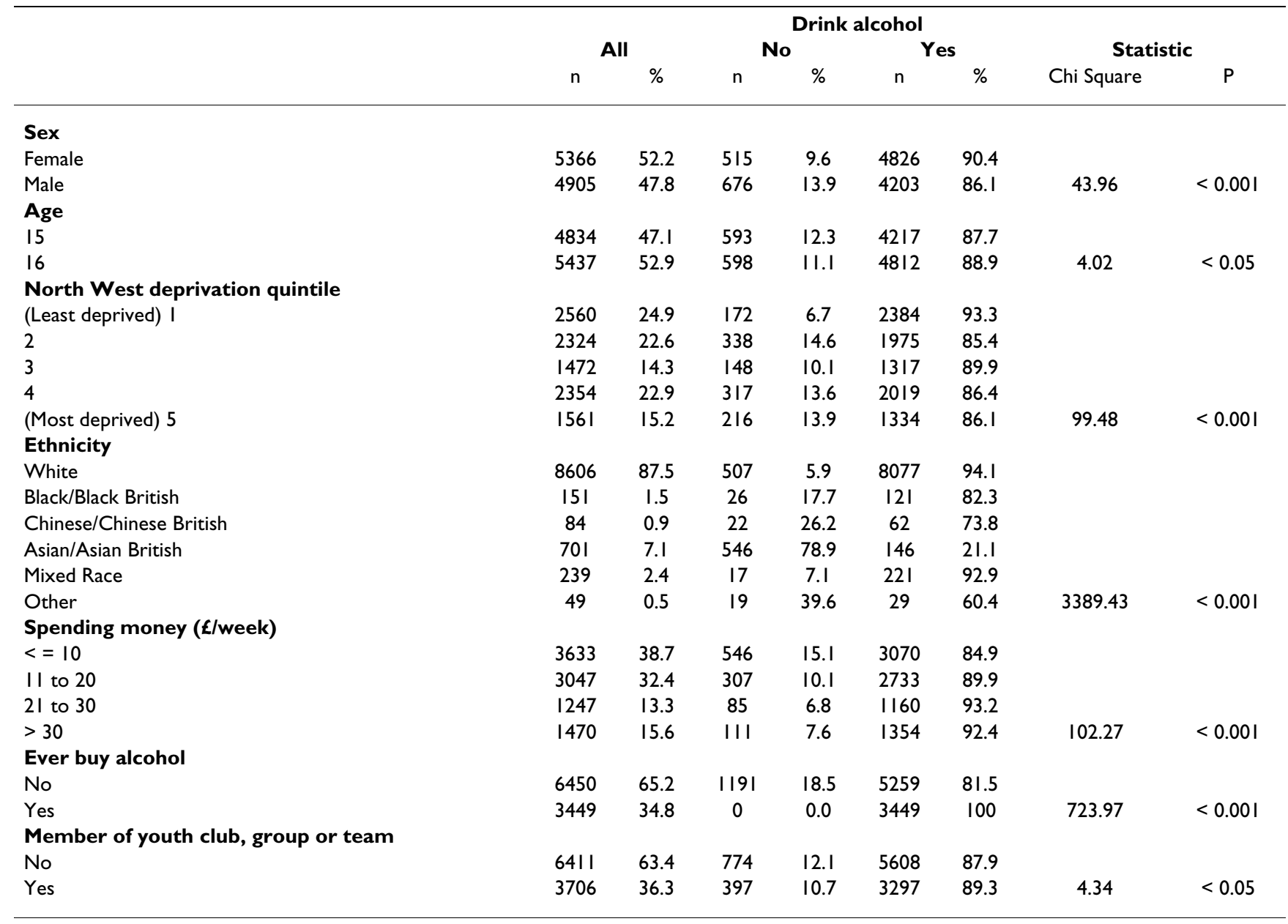

Analyses utilise chi squared. Samples sizes vary slightly between analyses due to some respondents not completing all questions.

$32.1 \%$ to $50.4 \%$. The combined effects of these increases meant that the proportion of individuals showing "all drinking risks" was four times higher in those that do buy alcohol themselves compared with those that do (Table 2).

Being a member of a youth club, group or team was linked to reductions in both frequency of drinking and drinking in public settings. However, it was linked to an increase in bingeing (Table 2). This mixed effect means that such membership had no significant relationship with whether individuals were in the composite "any drinking risk" category but was negatively related to being in "all drinking risks". Additional factors also strongly related to risky drinking behaviour were accessing alcohol through others. Here, getting alcohol from older siblings, friends (both under and over 18), and adults outside shops were all predictors of increased binge, frequent and public drinking (Table 2). Covertly taking alcohol from parents was also a predictor of frequent and public drinking. Importantly however, where parents bought alcohol for their children this had the opposite effect and was related to reductions in all individual risky drinking categories and in both "any drinking risk" and "all drinking risks" measures (Table 2).

Using logistic regression to adjust for confounding factors, Table 3 shows independent relationships between risky drinking behaviours and predictive variables. Here, binge drinking is associated with being male, Asian/Asian British, having more than $£ 10$ per week spending money and personal purchase of alcohol. Being bought alcohol by older siblings or friends were both also associated with bingeing. However, being given alcohol by parents remained a protective factor against bingeing (Table 3). Frequent drinking was also strongly associated with being male, having more spending money and personal purchase of alcohol. Further, as well as older siblings and friends (over 18) buying youths alcohol, getting adults outside shops to buy it and covertly taking it from parents were both predictors of frequent use. Only being a member of a youth club, group or team was protective against 
Table 2: Relationships between drinking behaviours and consumers' demographics, methods of accessing alcohol and income

\begin{tabular}{|c|c|c|c|c|c|c|c|c|c|c|c|c|c|c|c|c|}
\hline & & \multicolumn{3}{|c|}{ Binge drink } & \multicolumn{3}{|c|}{ Frequently drink } & \multicolumn{3}{|c|}{$\begin{array}{l}\text { Drinking behaviours' } \\
\text { Drink in public setting }\end{array}$} & \multicolumn{3}{|c|}{ Any drinking Risks } & \multicolumn{3}{|c|}{ All Drinking Risks } \\
\hline & & n (Yes) & $\%$ & $P$ & n (Yes) & $\%$ & $P$ & n (Yes) & $\%$ & $P$ & n (Yes) & $\%$ & $P$ & n (Yes) & $\%$ & $\mathrm{P}$ \\
\hline Sex & Female & 1672 & 34.6 & & 1002 & 21.2 & & 2339 & 50.4 & & 3169 & 65.7 & & 348 & 7.7 & \\
\hline & Male & 1755 & 41.8 & $<0.001$ & 1146 & 28.1 & $<0.001$ & 1998 & 49.0 & 0.191 & 2877 & 68.5 & $<0.01$ & 462 & 11.7 & $<0.001$ \\
\hline Age & 15 & 1513 & 35.9 & & 892 & 21.8 & & 1904 & 46.9 & & 2715 & 64.4 & & 295 & 7.5 & \\
\hline & 16 & 1914 & 39.8 & $<0.001$ & 1256 & 26.7 & $<0.001$ & 2433 & 52.2 & $<0.001$ & 3331 & 69.2 & $<0.001$ & 515 & 11.3 & $<0.001$ \\
\hline Deprivation quintile & (Least deprived) I & 873 & 36.6 & & 539 & 23.0 & & 1047 & 45.1 & & 1535 & 64.4 & & 194 & 8.5 & \\
\hline & 2 & 775 & 39.2 & & 448 & 23.3 & & 925 & 48.6 & & 1339 & 67.8 & & 154 & 8.3 & \\
\hline & 3 & 515 & 39.1 & & 325 & 25.1 & & 639 & 50.4 & & 879 & 66.7 & & 128 & 10.3 & \\
\hline & 4 & 767 & 38.0 & & 509 & 26.0 & & 1046 & 53.6 & & 1383 & 68.5 & & 201 & 10.6 & \\
\hline & (Most deprived) 5 & 497 & 37.3 & 0.38 & 327 & 25.3 & 0.117 & 680 & 53.4 & $<0.001$ & 910 & 68.2 & $<0.05$ & 133 & 10.8 & $<0.05$ \\
\hline Ethnicity & White & $3|2|$ & 38.6 & & 1877 & 23.8 & & 3869 & 49.5 & & 5409 & 67.0 & & 724 & 9.5 & \\
\hline & Black/Black British & 25 & 20.7 & & 19 & 16.4 & & 51 & 44.0 & & 63 & 52.1 & & 2 & 1.8 & \\
\hline & Chinese/Chinese British & 15 & 24.2 & & 14 & 23.7 & & 21 & 35.6 & & 31 & 50.0 & & 5 & 8.9 & \\
\hline & Asian/Asian British & 44 & 30.1 & & 43 & 30.1 & & 64 & 49.2 & & 91 & 62.3 & & 10 & 7.8 & \\
\hline & Mixed Race & 83 & 37.6 & & 58 & 26.7 & & 133 & 61.9 & & 168 & 76.0 & & 26 & 12.3 & \\
\hline & Other & 8 & 27.6 & $<0.001$ & 8 & 30.8 & 0.143 & 17 & 63.0 & $<0.005$ & 22 & 75.9 & $<0.001$ & 2 & 8.3 & 0.069 \\
\hline Spending money ( $\mathrm{f} /$ & $<=10$ & 951 & 31.0 & & 454 & 15.2 & & 1110 & 37.9 & & 1716 & 55.9 & & 117 & 4.1 & \\
\hline & 11 to 20 & 1152 & 42.2 & & 670 & 25.0 & & 1414 & 53.4 & & 1927 & 70.5 & & 280 & 10.8 & \\
\hline & 21 to 30 & 522 & 45.0 & & 372 & 32.5 & & 661 & 58.5 & & 880 & 75.9 & & 162 & 14.5 & \\
\hline & $>30$ & 628 & 46.4 & $<0.001$ & 494 & 37.1 & $<0.001$ & 861 & 64.8 & $<0.001$ & 1105 & 81.6 & $<0.001$ & 212 & 16.2 & $<0.001$ \\
\hline Ever buy alcohol & No & 1689 & 32.1 & & 831 & 16.3 & & 1739 & 33.1 & & 2958 & 56.2 & & 221 & 4.3 & \\
\hline & Yes & 1737 & 50.4 & $<0.001$ & 1315 & 38.8 & $<0.001$ & 2596 & 75.3 & $<0.001$ & 3086 & 89.5 & $<0.001$ & 588 & 17.3 & $<0.001$ \\
\hline Member of youth club, & No & 2070 & 36.9 & & 1426 & 26.1 & & 2769 & 51.0 & & 3796 & 67.7 & & 530 & 10.0 & \\
\hline & Yes & 1317 & 39.9 & $<0.005$ & 686 & 21.4 & $<0.001$ & 1512 & 47.8 & $<0.005$ & 2169 & 65.8 & 0.065 & 268 & 8.7 & $<0.05$ \\
\hline $\begin{array}{l}\text { Others buying youths } \\
\text { alcohol }\end{array}$ & & & & & & & & & & & & & & & & \\
\hline Parents & No & 1948 & 41.3 & & $|25|$ & 27.1 & & 2833 & 64.0 & & 3550 & 75.3 & & 522 & 12.1 & \\
\hline & Yes & 1479 & 34.5 & $<0.001$ & 897 & 21.5 & $<0.001$ & 1504 & 35.0 & $<0.001$ & 2496 & 58.2 & $<0.001$ & 288 & 6.9 & $<0.001$ \\
\hline Older siblings & No & 2908 & 37.0 & & 1803 & 23.5 & & 3695 & 48.8 & & 5165 & 65.7 & & 675 & 9.2 & \\
\hline & Yes & 519 & 45.2 & $<0.001$ & 345 & 30.7 & $<0.001$ & 642 & 56.0 & $<0.001$ & 881 & 76.8 & $<0.001$ & 135 & 12.0 & $<0.005$ \\
\hline Friends (over 18) & No & 2076 & 34.3 & & 1258 & 21.4 & & 2464 & 42.8 & & 3612 & 59.8 & & 454 & 8.1 & \\
\hline & Yes & $135 \mid$ & 45.6 & $<0.001$ & 890 & 30.6 & $<0.001$ & 1873 & 63.2 & $<0.001$ & 2434 & 82.1 & $<0.001$ & 356 & 12.3 & $<0.001$ \\
\hline Friends (under 18) & No & 2662 & 36.7 & & 1656 & 23.5 & & 3241 & 46.6 & & 4647 & 64.1 & & 605 & 8.9 & \\
\hline & Yes & 765 & 43.5 & $<0.001$ & 492 & 28.4 & $<0.001$ & 1096 & 62.4 & $<0.001$ & 1399 & 79.6 & $<0.001$ & 205 & 11.8 & $<0.001$ \\
\hline Take/steal from parents & No & 3157 & 37.9 & & 1916 & 23.6 & & 3959 & 49.3 & & 5528 & 66.4 & & 728 & 9.3 & \\
\hline & Yes & 270 & 39.4 & 0.44 & 232 & 34.8 & $<0.001$ & 378 & 55.2 & $<0.005$ & 518 & 75.6 & $<0.001$ & 82 & 12.3 & $<0.05$ \\
\hline
\end{tabular}




Binge drink $\quad$ Frequently drink Drink in public settings
AOR $(95 \% \mathrm{Cl}) \quad$ P $\quad$ AOR $(95 \% \mathrm{Cl})$

gs

Any risk
AOR $(95 \% \mathrm{Cl})$

7704

7704

Ref

Ref

$1.35(1.20-1.53)$ Ref

Male

Age

Deprivation quintile

(Least deprived) ।

2

$1.06(0.96-1.18)$ Ref

$1.16(0.95-1.42)$

$1.21(0.97-1.51)$

$1.09(0.86-1.39)$

(Most deprived) 5

Black/Black British

Chinese/Chinese British

Asian/Asian British

$0.66(0.33-1.29)$

$0.81(0.37-1.74)$

$1.70(1.01-2.86)$

Mixed Race

Other

$0.80(0.29-2.20)$

$$
\text { Ref }
$$

Spending money $(\boldsymbol{t})$

II to 20

21 to 30

$1.38(1.21-1.58)$

$1.50(1.28-1.76)$

$1.50(1.27-1.78)<0.001$ Ref

$<0.001 \quad 1.46(1.27-1.68)<0.001$
Ref

$11(0.98-1.25) \quad 0.091$

I. $12(0.99-1.26)$

$$
\text { Ref }
$$

Ref

$0.151 \quad 0.99(0.80-1.23)$

$1.15(0.92-1.43)$

0.939

$0.456 \quad 1.17(0.96-1.42)$

0.225
0.113

$1.26(1.01-1.57)$

$1.33(1.06-1.69)$

$1.17(0.93-1.48)$

$$
\text { Ref }
$$

$$
\text { Ref }
$$

$0.583-0.50(0.20-1.22)$

$0.83(0.39-1.78)$

0.128

$0.93(0.43-2.01)$

$0.91(0.39-2.13)$

$1.62(0.90-2.94)$

$1.04(0.59-1.82)$

0.859

$2.02(0.98-4.13)$

$.54(0.45-5.29)$

$$
\text { Ref }
$$

$$
\text { Ref }
$$

$1.51(1.30-1.76)$

$2.18(1.81-2.36)<0.00$

$1.51(1.30-1.76)$
$1.72(1.42-2.08)$

$2.01(1.69-2.39)$

Ref

$85(1.64-2.09)$

$2.37(1.98-2.84)<0.001$

Ref
$5.72(4.96-6.60)$

Ref

Ref

11 ( $10.96-1.29)$ Ref

.09 (0.97-1.22)

$$
\text { Ref }
$$

1.27 (1.01-1.58)

$1.24(1.00-1.53)$

$1.23(1.01-1.51)$

0.178

1.15 (0.89-1.49)

$$
\text { Ref }
$$

$0.58(0.28-1.19)$

$0.72(0.31-1.69)$

$1.62(0.94-2.79)$

$1.97(0.96-4.04)$

$$
\text { Ref }
$$

$0.90(0.80-1.00)$

$1.09(0.98-1.21)$

0.128

0.7 ( $(0.63-0.8 I)$

$<0.001$

$\begin{array}{cccc}\text { Ref } & & \text { Ref } & \\ 0.82(0.73-0.92) & <0.005 & 1.00(0.88-1.15) & 0.954\end{array}$

I.31 $(1.12-1.52)<0.005$

Ref

Ref

$1.19(1.05-1.35)<0.01$

Ref

$0.97(0.82-1.15)$

$\operatorname{Re}$

$0.89(0.75-1.06)$
I.40 (1.24-1.58) < 0.001

Ref

Take/steal from parents
$1.20(1.02-1.43)$ Ref

$1.43(1.26-1.63)<0.001$$$
\text { Ref }
$$

1.09 (0.94-1.28) Ref

$(0.45-0.57)$

Ref

I.31 (1.08-1.58)

Ref

$2.13(1.86-2.45)$

$1.74(1.47-2.07)$ Ref

$4.84(3.85-6.09)$

Ref

I.33 $(1.09-1.63)<0.01$

$1.09(0.85-1.40)$

\section{$<0.001$}

$1.47(1.28-1.68)$

$1.90(1.57-2.30)<0.001 \quad 2.36(1.79-3.10)<0.001$

$2.25(1.82-2.79)<0.001 \quad 3.04(2.26-4.09)<0.001$

$$
\text { Ref }
$$

$3.11(2.37-4.07)$ Ref

$2(5.02-6.97)$

Ref
Ref

$<0.001$

$0.92(0.81-1.04)$

$0.192 \quad 0.77(0.66-0.90)$

$<0.005$

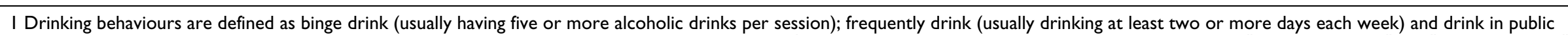

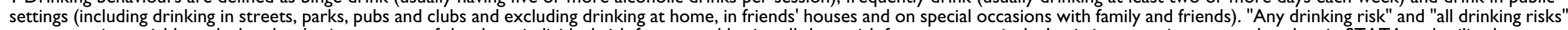
are composite variables calculated as having any one of the three individual risk factors and having all three risk factors respectively. Logistic regression was undertaken in STATA and utilised

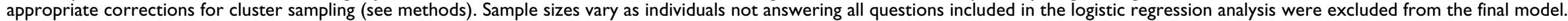
$A O R=$ Adjusted Odds Ratio. Ref $=$ Reference category. $A O R=$ Adjusted Odds Ratio. Ref $=$ Reference category. 
frequent use. In contrast to other risk factors, drinking in public places was higher in females (although not quite significantly so) and increased with deprivation up to quintile four (Table 3). It was also strongly related to both youths buying their own alcohol and levels of spending money available. Older siblings, friends and adults outside shops buying youths alcohol were all positively associated with increased public drinking. Again however, parents buying youths alcohol was protective against drinking in public settings (Table 3 ).

A parent buying their child alcohol was also protective against both composite factors of "any drinking risk" and "all drinking risks", while being a member of a youth group or team was protective against "all drinking risks" but had no significant relationship with "any drinking risk". However, youths buying their own alcohol, getting alcohol from adults outside shops, from friends, and having more money to spend were all related to having "any drinking risk" and "all drinking risks", while purchase of alcohol by older siblings was related to "any drinking risk" but not "all drinking risks" (Table 3 ).

\section{Discussion}

Although this is one of the largest samples of youths to have been examined for drinking behaviour in England, it was not designed to be representative of the population. In addition, in order to ensure truthful responses the survey asked a minimum on personal demographics and consequently deprivation was assigned utilising school locations rather than more sensitive individual measures. Such factors limit both the analyses possible within the study and the opportunity to extrapolate data to wider populations. Further, as a cross-sectional study our results do not address cause and effect. However, the design of the study has allowed detailed examinations of relationships between risky alcohol consumption, sources of alcohol, places of consumption and other individual behavioural and demographic characteristics.

In fact, levels of at least any alcohol consumption by study participants (here, $87.9 \%$ ) were broadly consistent with national data that show a prevalence of any alcohol consumption in the last twelve months of 91\% (aged 15-16) [8]. However, rather than conducting detailed analysis of factors relating to any alcohol use, we have examined factors predicting risky drinking among youths that consume alcohol. Such analyses acknowledge that the vast majority of 15 to 16 year old youths in the UK drink alcohol (at least occasionally), that alcohol consumption in controlled environments (e.g. with family) may not always be detrimental to health $[31,46]$ and that identifying factors relating specifically to alcohol misuse (c.v. consumption) are a critical part of developing harm reducing interventions.
Results identify binge, frequent and public drinking as all being strongly related to amounts of spending money youths have available. Such information offers at least three possible points for intervention. Firstly interventions could aim to reduce money available to young people or advise parents on improving their monitoring of what youths spend money on. Currently, teenagers (aged $12-16)$ in the UK typically receive almost $£ 10$ pocket money a week from parents [47] while over a third (37\%) of 14 to 15 year olds work in a regular paid job during school term time [48]. However, public health considerations of how providing money to youths affects behaviour or of how parents may better control expenditure are poorly developed. Secondly, increasing the cost of alcohol may reduce access to alcohol and thus consumption. Unfortunately, in real terms affordability of alcohol has increased in the UK [49] and despite good evidence that increased costs can reduce alcohol consumption, particularly among young people[50], there appear to be no moves to increase alcohol taxes [51] or allow areas to manage alcohol prices locally through other means [52]. Finally, organised social and sporting activities which are attractive to young people should be made more widely available as an alternative to getting drunk. Currently there is little international evidence that providing specifically alcohol-free diversionary activities will reduce youth alcohol consumption [53]. However, our results (Table 3) at least support findings elsewhere that individuals involved in youth groups and sporting activities are less likely to exhibit risky drinking behaviours [54]. Some interventions have been developed in the UK and other countries with activities such as sports, theatre and crafts provided to encourage youths away from anti-social behaviour, including substance use $[53,55,56]$. However, such programmes currently affect only limited numbers of individuals in deprived areas $[55,56]$ and our results (Table 3) suggest risky drinking behaviours occur across all deprivation quintiles. Consequently, rather than tightly focused interventions, further exploration is required of wider population approaches including school-based after-school activities and parental roles in encouraging participation in sports and other social ventures. Further, with membership of such groups potentially associated with greater binge drinking (Table 2), provision of better entertainment options for youths should incorporate safer drinking messages for participants.

Related to available income but independently associated with increased binge, frequent and public drinking is individuals buying their own alcohol. Those who purchase their own drink are nearly six times more likely to drink in public settings, three times more likely to drink frequently and twice as likely to usually binge (Table 3 ). However, all such alcohol purchasing should be controlled. It is illegal 
to sell alcohol to anyone under 18 in the UK and a range of voluntary identity schemes (e.g. Challenge 21) are available to ensure that those trying to buy alcohol are aged 18 or over [52]. Local enforcement bodies (e.g. Trading Standards, police) can punish and even force closure of establishments that persistently sell alcohol to those underage. However, despite evidence that such interventions are effective [57], at least historically such powers have been used infrequently. Even with increased enforcement in recent years, over a fifth of targeted test purchases still result in a positive sale to a minor (England and Wales)[58]. Moreover, in our sample approximately a third of the individuals had bought alcohol for themselves (39.6\% of those that drink). With greater investment in enforcing underage sales restrictions these proportions could be radically reduced. Further, partnership working between alcohol retailers, health services and enforcement sectors could develop interventions to help those identified trying to buy alcohol underage.

Not all alcohol consumed by youths is purchased by them. In this study many individuals used older siblings, friends and even strangers outside alcohol retail outlets to obtain alcohol. Obtaining alcohol from older siblings was related to binge, frequent and public drinking and again consideration should be given to informing parents of additional risks faced by younger siblings from alcohol provided by older brothers and sisters [59]. Obtaining alcohol from adults outside shops was especially related to drinking in public settings. Not only does this allow youths to get drunk but it also requires young people to interact with adult strangers, potentially exposing children to the risk of sexual abuse. However, partnership working could allow adults who buy alcohol for underage youths to be identified and laws preventing such purchases enforced.

Finally, and in stark contrast to other forms of obtaining alcohol, youths whose parents buy them alcohol were less likely to binge and only half as likely to drink in public settings. Moreover, they were also significantly less likely to be in the most harmful group showing all three risk behaviours (Table 3). Such findings suggest that parental provision of alcohol, at least to youths who already consume, may reduce their immediate risk of hazardous and harmful consumption behaviours. These findings are consistent with other studies which identify drinking with parents as protective against higher alcohol consumption [60]. Further, although early initiation into alcohol use appears to be related to later problem drinking, those initiated in a family environment are much less likely to become problem drinkers than those initiated outside the family [61]. Models of family drinking in other (e.g. Mediterranean) countries, where alcohol is routinely consumed in the family environment but levels of binge drinking and anti-social behaviour associated with alcohol are lower than in the UK, are also at least consistent with a positive effects of parental alcohol provision. Such family consumption may help open up an early dialogue about alcohol between parents and children. Furthermore, it allows youths to experiment with alcohol in a family setting with positive parental role models rather than outside the family with pressure from peers to consume to excess. More research is needed on any positive effects of consuming alcohol in family environments. In the meantime however, it is essential that public health messages do not discourage parents from consuming modest amounts of alcohol with their children as such changes may actually increase drinking behaviours most damaging to youths' health.

\section{Conclusion}

A combination of increases in binge, frequent and public drinking, mean alcohol is becoming one of the major threats to young people's health in many developed countries [6]. Such behaviour not only causes direct damage in the short term through accidents, violence and overdose but, in the long term, can lead to early onset of alcoholrelated diseases such as liver cirrhosis [62]. Related antisocial behaviour disturbs and sometimes destroys communities and renders public spaces (e.g. parks and city centres) no-go areas for large numbers of individuals [63]. Here, we have shown strong links between the risky consumption of alcohol and factors such as expendable income and underage sales. We have also identified potentially protective factors against such consumption including parental provision of alcohol and engagement in other youth activities. In turn such intelligence points towards a series of interventions including: limiting and monitoring young people's funds; increasing costs of alcohol; providing and promoting participation in sporting and other social activities for youths; and identifying and closing all retailers selling to those underage. Such interventions are not expensive, complicated or difficult to implement. They require parents to examine children's expenditure and perhaps even moderately consume alcohol with them, educating them about its use and providing positive role models for responsible consumption. They also require the political willpower to eradicate any parts of the alcohol industry that provide alcohol to juniors. However, the effectiveness of such measures will still rely on youths having alternatives to alcohol and consequently local authorities and governments prioritising legitimate youth activities over more bars and nightclubs.

\section{Competing interests}

The author(s) declare that they have no competing interests. 


\section{Authors' contributions}

$\mathrm{MAB}$ analysed the data and produced the manuscript. $\mathrm{KH}$ and MM assisted in production of the manuscript. KT, SH and EF assisted with data analysis. TA conducted the survey. DH edited the manuscript.

\section{Acknowledgements}

This work would not have been possible without the cooperation and dedicated work of staff in all participating schools and Trading Standards Offices in the North West. We are also grateful to the North West Regional Alcohol Strategic Group who coordinated input from all participating agencies.

\section{References}

I. World Health Organization: World health report 2002: reducing risks, promoting healthy life. Geneva 2002.

2. World Health Assembly: Public health problems causes by harmful use of alcohol. WHA58.26. Geneva 2005 [http://www.who.int/ substance abusel wha resolution 5826 public health problems alcohol.pdf]. (accessed July 2006)

3. World Health Organization: Public health problems caused by harmful use of alcohol [online]. Geneva 2005 [http://www.who.int/gb/ebwha/ pdf files/WHA58/A58 18-en.pdf]. (accessed July 2006).

4. Rehm J, Rehn N, Room R, Monteiro M, Gmel G, Jernigan D, Frick U: The global distribution of average volume of alcohol consumption and patterns of drinking. Eur Addict Res 2003, 9:147-156.

5. Rehm J, Room R, Monteiro M, Gmel G, Graham K, Rehn N, Sempos $\mathrm{CT}$, Jernigan $\mathrm{D}$ : Alcohol as a risk factor for global burden of disease. Eur Addict Res 2003, 9:157-164.

6. World Health Organization Regional Office for Europe: Framework for alcohol policy in the WHO European Region Copenhagen; 2006.

7. Commission of the European Communities: Communication from the Commission to the Council, the European Parliament, the European Economic and Social Committee and the Committee of the Regions: an EU strategy to support Member States in reducing alcohol-related harm Brussels; 2006.

8. Hibell B, Andersson B, Bjarnasson T, Ahlström S, Balakireva $O$, Kokkevi A, Morgan M: The ESPAD report 2003: alcohol and other drug use among students in 35 European countries Stockholm: CAN; 2004.

9. Room R, Babor T, Rehm : Alcohol and public health. Lancet 2005, 365:519-530.

10. Bellis MA, Hughes K, Tocque K, Hennell T, Humphrey G, Wyke S: Assessing and communicating the health and judicial impact of alcohol use. Public Health 2005, I 19:253-26I.

11. Hughes K, Tocque K, Humphrey G, Bellis MA: Taking measures: a situational analysis of alcohol in the North West Liverpool: Centre for Public Health; 2004.

12. World Health Organization: Facts on youth violence and alcohol. Geneva 2006.

13. Best D, Manning V, Gossop M, Gross S, Strang J: Excessive drinking and other problem behaviours among 14-16 year old schoolchildren. Addict Behav 2006, 31: |424-1435.

14. Traeen B, Kvalum IL: Sex under the influence of alcohol among Norwegian adolescents. Addiction 1996, 91:995-1006.

15. Ramsey M, Partridge S: Drug misuse declared in 1998: results from the British Crime Survey London: Home Office; 1999.

16. Leon DA, McCambridge J: Liver cirrhosis mortality rates in Britain from 1950-2002: an analysis of routine data. Lancet 2006, 367:52-56

17. Morleo M, Dedman D, Hughes K, Hooper J, Tocque K, Bellis MA: Regional alcohol indicators for the North West of England 2006 Liverpool: Centre for Public Health; 2006.

18. World Health Organization: Lexicon of alcohol and drug terms published by the World Health Organization 2006 [http://www.who.int/ substance abuse/terminology/who lexicon/en/]. (accessed July 2006).

19. Department of Health: Alcohol Needs Assessment Research Project (ANARP): the 2004 national alcohol needs assessment for England. London; 2005. Supplementary information available from [http://www.nwph.net/ alcohol]. (accessed July 2006).
20. Currie C, Roberts C, Morgan A, Smith R, Settertobulte W, Samdal O, Barnekow Ramussen V: Young people's health in context: health behaviour in school-aged children (HBSC) study: international report from the 2001/2002 study. Health Policy for Children and Adolescents, No. 4 Copenhagen: World Health Organization Regional Office for Europe; 2004.

21. Naimi T, Lipscomb L, Brewer R, Gilbert BC: Binge drinking in the preconception period and the risk of unintended pregnancy: implications for women and their children. Pediatrics 2003, III:II36-II4I.

22. Wood M: Perceptions and experience of anti-social behaviour: findings from the 2003/04 British Crime Survey. Home Office online report 49/04 2004 [http://www.homeoffice.gov.uk/rds/pdfs04/rdsolr4904.pdf]. London: Home Office (accessed July 2006).

23. Social Exclusion Unit: Teenage pregnancy. London 1999.

24. Prime Minister's Strategy Unit: Alcohol misuse: how much does it cost? London 2003.

25. Engels RCME, Knibbe RA: Young people's alcohol consumption from a European perspective: risks and benefits. Eur J Clin Nutr 2000, 54:S52-S55.

26. Hingson RW, Heeren T, Winter MR: Age at drinking onset and alcohol dependence. Arch Pediatr Adolesc Med 2006, 160:739-746.

27. Pitkänen T, Lyyra A, Pulkkinen L: Age of onset of drinking and the use of alcohol in adulthood: a follow-up study from age 8-42 for females and males. Addiction 2005, 100:652-661.

28. Pederson W, Skrondal A: Alcohol consumption debut: predictors and consequences. J Stud Alcohol 1998, 59:32-42.

29. Casswell S, Pledger M, Pratrap S: Trajectories of drinking from 18 to 26 years: identification and prediction. Addiction 2002, 97:|427- 1437.

30. Oesterle S, Hill KG, Hawkins JD, Guo J, Catalano RF, Abbott RD: Adolescent heavy episodic drinking trajectories and health in young adulthood. J Stud Alcohol 2004, 65:204-212.

3I. Wells S, Graham K, Speechley M, Koval JJ: Drinking patterns, drinking contexts and alcohol-related aggression among late adolescent and young adult drinkers. Addiction 2005, 100:933-944.

32. Swahn MH, Simon TR, Hammig BJ, Guerrero JL: Alcohol-consumption behaviors and risk for physical fighting and injuries among adolescent drinkers. Addict Behav 2004, 29:959-963.

33. Ham LS, Hope DA: College students and problematic drinking: a literature review. Clin Psychol Rev 2003, 23:719-759.

34. Kuntsche E, Rhem J, Gmel G: Characteristics of binge drinkers in Europe. Soc Sci Med 2004, 59:I I3-1 27.

35. Hawkins JD, Catalano RF, Miller JY: Risk and protective factors for alcohol and other drug problems in adolescence and early adulthood: implications for substance abuse prevention. Psychol Bull 1992, I I 2:64- 105.

36. Office for National Statistics: Corrected - 20//2/05 - T I2: quinary age groups and sex for health areas in the United Kingdom; estimated resident population; mid-2004 population estimates [http://www.statis tics.gov.uk/STATBASE/ssdataset.asp?vInk=9092]. $\frac{\text { (accessed July }}{2006 \text { ) }}$ 2006).

37. Scott N: Young people in the metropolitan borough of Sefton: substance use and misuse Sefton: Sefton Local Authority; 2002.

38. Pomfret A, Stelfox J, Bones A: Quality of life survey 2005, - young people Volume 3. Chester: Cheshire County Council; 2006.

39. Home Office: Alcohol industry must do more to tackle underage sales. 18th October 2006 [http://press.homeoffice.gov.uk/press-releases/ alcohol-industry-underage-sales]. (accessed January 23 ${ }^{\text {rd }} 2007$ )

40. Office of the Deputy Prime Minister: Indices of Deprivation 2004 - summary (revised) [http://www.communities.gov.uk/ index.asp?id=I | 28442]. (accessed July 2006).

41. Department for Education and Skills: Research and statistics gateway. [http://www.dfes.gov.uk/rsgateway/].

42. SPSS Inc: SPSS Base II 0 User Guide USA: SPSS Inc; 2001.

43. Levy PS, Lemeshow S: Sampling of populations: methods and applications 3rd edition. New York: John Wiley and Sons; 1999.

44. Cohen SB: An evaluation of alternative PC-based software packages developed for the analysis of complex survey data. Am Stat 1997, 5 I:285-292.

45. Stata Corporation: Stata reference manual. Release 6. College Station, TX; Stata Corporation 1999.

46. Forsyth A, Barnard M: Preferred drinking locations of Scottish adolescents. Health Place 2000, 6:105-115. 
47. Halifax: Children in London are 2006's pocket money winners. Halifax; April 2006 [http://www.hbosplc.com/media/pressreleases/articles/ halifax/2006-04-15-01.asp?fs=/media/press releases.asp]. (accessed $18^{\text {th }}$ July 2006)

48. Schools Health Education Unit: Trends - money: attitudes to earning, spending and saving money 1983-2004 Exeter: Schools Health Education Unit; 2005.

49. The Information Centre: Statistics on alcohol 2006 Leeds: The Information Centre; 2006.

50. Laixuthai A, Chaloupka F: Youth alcohol use and public policy. Contemp Policy Issues 1993, I I:70-8I.

5I. Prime Minister's Strategy Unit: Alcohol Harm Reduction Strategy for England. London 2004.

52. Hughes K, Bellis MA: Use of environmental alcohol strategies to tackle alcohol-related harm in nightlife: the UK experience. In European Monitoring Centre for Drugs and Drug Addiction. Thematic paper on environmental strategies in press.

53. Babor T, Caetano P, Casswell S, Edwards G, Giesbrecht N, Graham K, Grube J, Gruenewald P, Hill L, Holder H, Homel R, Österberg E, Rehm J, Room R, Rossow I: Alcohol: no ordinary commodity: research and public policy Oxford: Oxford University Press; 2003.

54. Fredricks JA, Eccles JS: Is extracurricular participation associated with beneficial outcomes? Concurrent and longitudinal relations. Dev Psychol 2006, 42:698-7/3.

55. Loxley C, Curtin L, Brown R: Summer splash schemes 2000: findings from six case studies London: Home Office; 2002.

56. Sport England: Positive Futures: a review of impact and good practice 2002 [http://www.sportdevelopment.org.uk/pfsummary2002.pdf]. London: Sport England (accessed 20th July 2006).

57. Wagenaar AC, Toomey TL, Erickson DJ: Preventing youth access to alcohol: outcomes from a multi-community time-series trial. Addiction 2005, 100:335-345.

58. Police Standards Unit. In Lessons from the Christmas 2005 Alcohol Misuse Enforcement Campaign London: Home Office; 2006.

59. Trim RS, Leuthe $E$, Chassin $L$ : Sibling influence on alcohol use in a young adult, high-risk sample. J Stud Alcohol 2006, 67:39I-398.

60. Foley KL, Altman D, Durant RH, Wolfson M: Adults' approval and adolescents' alcohol use. J Adolesc Health 2004, 35:345.e I 7-26.

61. Warner LA, White HR: Longitudinal effects of age at onset and first drinking situations on problem drinking. Subst Use Misuse 2003, 38: 1983-2016.

62. Baker A, Rooney C: Recent trends in alcohol-related mortality, and the impact of ICD-IO on the monitoring of these deaths in England and Wales. In Health Statistics Quarterly 17 London: Office for National Statistics; 2003:5- I4.

63. Tierney J, Hobbs D: Alcohol-related crime and disorder data: guidance for local partnerships London: Home Office; 2003.

Publish with Bio Med Central and every scientist can read your work free of charge

"BioMed Central will be the most significant development for disseminating the results of biomedical research in our lifetime. "

Sir Paul Nurse, Cancer Research UK

Your research papers will be:

- available free of charge to the entire biomedical community

- peer reviewed and published immediately upon acceptance

- cited in PubMed and archived on PubMed Central

- yours - you keep the copyright

Submit your manuscript here:

http://www.biomedcentral.com/info/publishing_adv.asp
BioMedcentral 